\title{
GEOQUÍMICA E AMBIÊNCIA TECTÔNICA DE METABASITOS DO ALTO E MÉDIO VALE DO RIBEIRA, SÃO PAULO E PARANÁ
}

\author{
MARIA HELOÍSA BARROS DE OLIVEIRA FRASCÁ*, GINALDO ADEMAR DA CRUZ CAMPANHA**, MÁRIO \\ CESAR HEREDIA DE FIGUEIREDO*** \& GEORG ROBERT SADOWSKI**
}

\begin{abstract}
GEOCHEMISTRY AND TECTONIC SETTING OF METABASITES FROM THE UPPER AND MIDDLE RIBEIRA VALLEY, SÃO PAULO E PARANÁ In order to stablish tectonic settings, petrographic and litochemical analyses were carried on samples of metabasic rocks from the Upper and Middle Ribeira Valley, between the townships of Apiaí, Iporanga and Barra do Turvo, São Paulo State. The metabasites are considered to be of Mesoproterozoic age and their samples were collected both to the north and south of the Ribeira Lineament. Basic rocks from the Apiai Gabbro, the Betari Dyke and another smaller dyke were also sampled, whith the purpose of to compare these magmatisms. Conclusions driven from the analyses are: a) $\mathrm{SiO}_{2}$ contents are very homogeneous; only two samples of metabasites fell out of the basalt field; b) based on their major element composition, ali samples exhibit tholeiitic characteristics; c) the metabasites of the Ribeira Subgroup may be classified into two different assemblages: one, which includes the samples collected to the north of the Ribeira Lineament, is high in $\mathrm{Ca}, \mathrm{Al}$ and low in $\mathrm{P}, \mathrm{Ti}, \mathrm{Zr}, \mathrm{Y}, \mathrm{Sr}$, with peculiarities similar to those found in basalts of modern island arcs; the other, collected to the south of the Lineament, is enriched in $\mathrm{Na}, \mathrm{Fe}, \mathrm{Ti}, \mathrm{Zr}, \mathrm{Y}, \mathrm{Sr}$, and could be related to the compositions of modern middle ocean ridge basalts; d) the composition of the Apiaí Gabbro also displays similarities with modern middle ocean ridge basalts; e) the diabase dykes are strongly enriched in Ti, P, Fe, Sr, Zr, Y a fact that links them to the HTi basalts whith geochemical features cornmon to the Meso-Cenozoic basaltic magmatism of the Paraná Basin and to other plateau and continental rift basalts.
\end{abstract}

Keywords: Apiaí, Ribeira, Açungui, Proterozoic, basic magmatism, geochemistry

RESUMO Neste trabalho foi efetuado estudo petrográfico e geoquímico visando o estabelecimento do paleoambiente tectônico de rochas metabásicas encontradas na região do Alto e Médio Vale do Ribeira, entre as cidades de Apiá. Iporanga e Barra do Turvo no Estado de São Paulo. Os metabasitos são considerados como de idade mesoproterozóica e foram coletados de corpos situados tanto a norte como a sul do Lineamento Ribeira. Na região tambem há ocorrência de rochas básicas, das quais foram coletadas amostras provenientes do Gabro de Apiaí e de diabásios do Dique do Betari e de outro menor, com o propósito de se caracterizar e comparar estes magmatismos. A análise dos dados obtidos permitiu as seguintes conclusões: a) as rochas apresentam grande homogeneidade quanto ao conteúdo em $\mathrm{SiO}_{2}$, e somente duas delas não se classificaram como basaltos; b) todas tem natureza tolética quanto aos elementos maiores; c) os metabasitos da Subgrupo Ribeira diferenciam-se em dois conjuntos: um, a norte do Lineamento Ribeira, é relativamente enriquecido em $\mathrm{Ca}$ e $\mathrm{Al}$ e pobre em $\mathrm{P}, \mathrm{Ti}, \mathrm{Zr}$, Y e Sr, e apresenta características similares às de basaltos de arcos de ilhas modernos; 0 outro, a sul do Lineamento Ribeira, é relativamente enriquecido em Na, Fe, Ti, Zr, Y e Sr, e guarda semelhanças com basaltos de cadeias meso-oceânicas modernas; d) o Gabro de Apiaí tem características geoquímicas de basaltos de cadeias meso-oceânicas modernas; e) os diques de diabásios, fortemente enriquecidos em Ti, $\mathrm{P}, \mathrm{Fe}, \mathrm{Sr}, \mathrm{Zr}$ e Y; são correlacionáveis aos basaltos HTi, com feições análogas às do magmatismo meso-cenozóico da Bacia do Paraná e de basaltos de platôs e riftes continentais.

Palavras chave: Apiaí, Ribeira, Açungui, Proterozóico, magmatismo básico, litoquímica

INTRODUÇ̃̃O $\mathrm{Na}$ região do Alto e Médio Vale do Ribeira (SP e PR), estudada no trecho entre Apiaí, Iporanga e Barra do Turvo por Campanha (1991), ocorrem expressivas associações metassedimentares e metavulcanossedimentares de baixo e médio graus metamórficos, incluídas classicamente no Grupo Açungui e consideradas de idade mesoproterozóica. Fazem parte do Cinturão Ribeira, de Almeida et al. (1973) e da Faixa de Dobramentos Apiaí, de Hasui et al. (1975) (Figura 1).

A paleoambiência tectônica desta região ainda tem sido objeto de variados estudos. Neste trabalho procurou-se, através da análise litoquímica de rochas metabásicas aí ocorrentes, dados que auxiliassem na caracterização dos protolitos e de sua ambiência tectônica. Particularmente a questão da existência ou não de rochas de fundo oceânico constitui-se num ponto chave na interpretação da tectônica proterozóica da região.

Embora não se constituam no objetivo principal deste trabalho, foram também analisadas amostras de rochas básicas intrusivas ocorrentes na região. Foram estudadas amostras do Gabro de Apiaí (de idade neoproterozóica) e de diques de diabásio (de idade meso - cenozóica). O objetivo implícito residia em verificar a capacidade dos métodos geoquímicos em discriminar rochas de outras idades, ambientes e colocação tectônica ocorrentes na região.

GEOLOGIA REGIONAL As rochas da região do Alto e Médio Vale do Ribeira (SP e PR), foram englobadas por Campanha et al. (1994, 1995) no Grupo Votuverava, do Supergrupo Açungui, subdividido, na região, no Subgrupo Lajeado, Formação Iporanga e Subgrupo Ribeira (este equivalente à Formação Perau no conceito de Chiodi Filho 1984, e Campanha et al. 1987) (Figura 2).

O Subgrupo Lajeado corresponde a uma plataforma carbonática, constituída por formaçoes terrígenas e carbonáticas alternadamente sobrepostas, intrudida em sua porção superior por um corpo gabróide, o Gabro de Apiaí. Este corpo já pertence ao Neoproterozóico, com idade de $850 \pm 85 \mathrm{Ma}$ (Daitx et al. 1990). O Subgrupo Lajeado limita-se com a Formação Iporanga através da zona de cisalhamento do Lineamento da Figueira.

A Formação Iporanga é constituída por metarritmitos finos, com intercalações de metarenitos, metaconglomerados e metabrechas polimíticas.

As principais ocorrências de rochas metabásicas encontram-se na área do Subgrupo Ribeira. Este constitui-se pre-

* Divisão de Geologia, Instituto de Pesquisas Tecnológicas -IPT, Caixa Postal 7141, CEP 01064-970, São Paulo, SP, Brasil, Fax (011) 869-6383, e-mail: mheloisa@ipt.br.

** Instituto de Geociências, Universidade de São Paulo, Caixa Postal 11348, CEP 05422-970, São Paulo, SP, Brasil, Fax (011) 818-3993, e-mail: ginaldo@usp.br, sadowski@usp.br. 


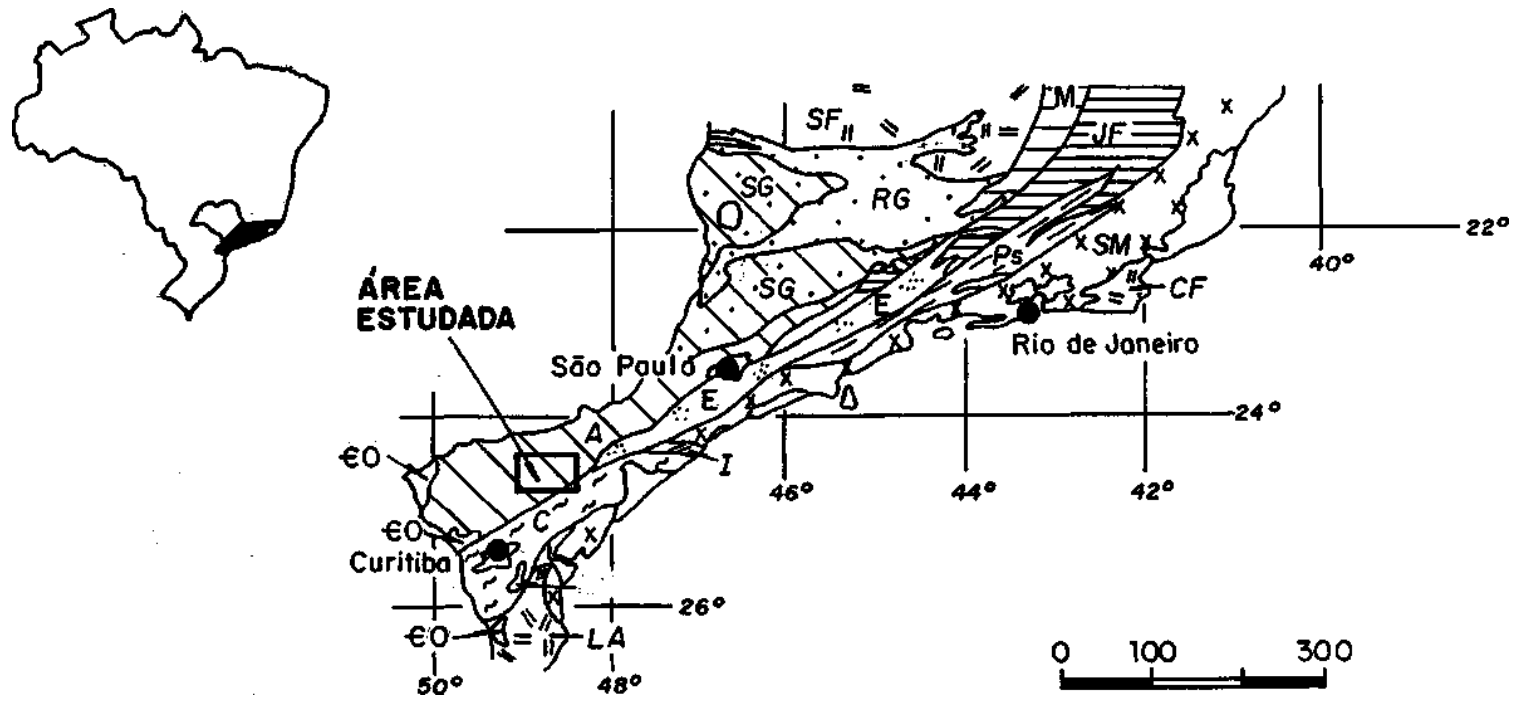

Figura 1 - Localização da área estudada dentro das principais unidades tectônicas pré-silurianas da região sudeste do Brasil. (A) Faixa de Dobramentos Apiaí; (E) Terreno Embu; (C) microplaca Curitiba; (LA) Bloco Luís Alves; (1) Bloco Itatins; (SM) microplaca Serra do Mar; (PS) Terreno Paraíba do Sul; (JF) Terreno Juiz de Fora; (M) Terreno Mantiqueira; (SG) Nappe de Socorro-Guaxupé; (RG) Faixa Alto Rio Grande; (SF) Craton do São Francisco; (CO) sequências sedimentares e vulcanossedimentares cambro-ordovicianas (baseado em Campos Neto \& Figueiredo 1995).

Figure 1 - Location of the studied area and its relationship with the main pre-Silurian tectonic units of the southeastern Brazil. (A) Apiai Fold Belt; (E) Embu Terrane; (C) Curitiba microplate; (LA) Luís Alves Block; (I) Itatins Block; (SM) Serra do Mar microplate; (PS) Paraíba do Sul Terrane; (JF) Juiz de Fora Terrane; (M) Mantiqueira Terrane; (SG) Nappe of Socorro-Guaxupé; (RG) Alto Rio Grande Belt; (SF) São Francisco Craton; (eO) Cambro-ordovician sedimentary and vulcanosedimentary sequences (based on Campos Neto \& Figueiredo 1995).

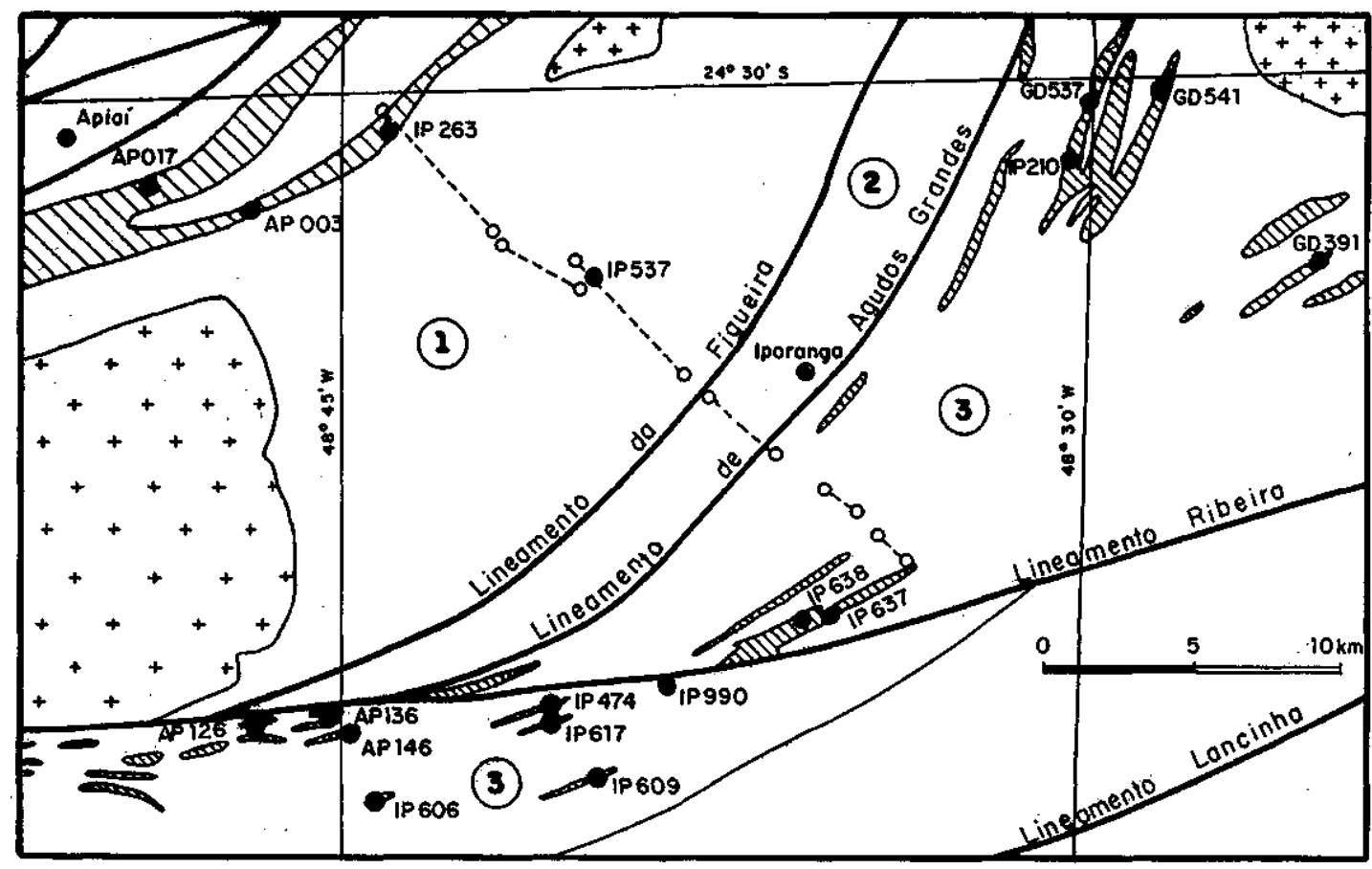

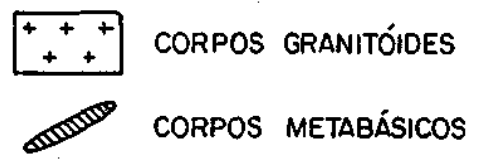

(1)

SUBGRUPO LAJEADO
(2)

\section{DIQUES DE DIABÁSIO \\ - PONTOS COM ANÁlises PETROGRÁFICA E QUIMICA}

Figura 2 - Mapa geológico simplificado da região estudada e de localização dos pontos de amostragem para análises petrográficas e químicas (Campanha et al. 1995).

Figure 2 - Simplified geological map of the studied region and of the analyzed sample location (Campanha et al 1995). 
dominantemente de metapelitos de granulação fina a muito fina, em geral fortemente deformados. Os metabasitos ali ocorrem na forma de corpos alongados, com espessuras da ordem de metros a poucas centenas de metros, concordantes com a foliação tectônica regional. Subordinadamente ocorrem metamargas, metacalcários, metarenitos, metaconglomerados oligomíticos, pequenas formações ferríferas e lâminas de metacherts.

O Subgrupo Ribeira é seccionado, na área, pelo Lineamento Ribeira. No bloco a norte deste, o grau metamórfico é fraco (zona da clorita) a incipiente, com estruturas sedimentares reliquiares em geral bem preservadas, apesar da forte deformação tectônica. Os metapelitos têm sido interpretados como associados a leques turbidíticos distais e folhelhos pelágicos. As rochas metabásicas associam-se predominantemente aos últimos (Campanha 1991). O bloco a sul do Lineamento Ribeira apresenta grau metamórfico pouco maior, em geral na zona da biotita. As estruturas reliquiares estão menos preservadas, porém a associação de protolitos é essencialmente semelhante à do bloco norte.

Foram mapeadas duas associações metabásicas (Campanha 1991). Uma apresenta composição relativamente pouco transformada, constituída por anfibolitos, actinolita anfibolitos, diopsídio granofels e plagioclásio-clorita xistos, enquanto que outra é formada por rochas que sofreram intensa alteração hidrotermal, gerando carbonato granofels. Em função dos objetivos do trabalho, visando a caracterização dos protolitos e de sua ambiência tectônica, são aqui estudadas apenas as rochas do primeiro grupo.

Ocorrem ainda, na área, alguns exemplares de diques de diabásio, provavelmente relacionados a episódios magmáticos do Mesozóico-Cenozóico, destacando-se aquele que condiciona os vales do rio Betari e do ribeirão das Pedras.

MÉTODO DE TRABALHO Para o presente estudo foram efetuadas análises petrográficas e químicas de rochas metabásicas e básicas, cujos pontos de amostragem, e sua distribuição, acham-se na Figura 2.

As análises petrográficas foram efetuadas em microscópio óptico de luz transmitida, com ênfase à mineralogia, relações texturais e microtectônica.

Para análise química, selecionaram-se preferencialmente amostras sem evidências de alteração intempérica ou metassomática, e que fossem representativas de corpos situados a norte e a sul do Lineamento Ribeira, de modo a se comparar as características das duas faixas do Subgrupo Ribeira.

Também foram selecionadas, para análises petrográfica e química, três amostras do Gabro de Apiaí, uma do Dique do Betari e outra de um dique menor.

As análises químicas foram executadas em 23 amostras, para os elementos maiores (óxidos de $\mathrm{Si}, \mathrm{Ti}, \mathrm{Fe}, \mathrm{Mg}, \mathrm{Ca}, \mathrm{Mn}$, $\mathrm{Na}, \mathrm{K}$ e P) e para Sr, Zr e Y, nos laboratórios da Geosol (Belo Horizonte, MG). Os métodos de determinação acham-se descritos na Tabela 1 .

A ausência de dados de perda ao fogo não se mostrou impeditiva, pois ao se recalcular os resultados químicos para a base anidra (i.e. seus totais a $100 \%$ ), os valores obtidos - e com os quais se construiu todos os diagramas apresentados - exibiram grande coerência interna e a relação elementos maiores/traços mostrou-se petrogeneticamente significativa. Considerou-se então os dados utilizáveis para os propósitos estabelecidos, ou seja, a comparação das composições químicas dos litotipos aqui estudados com aquelas típicas de rochas básicas de ambientes modernos disponíveis na literatura, visando interpretações paleoambientais.

CARACTERÍSTICAS PETROGRÁFICAS Os resultados das análises petrográficas das rochas básicas e metabásicas selecionadas encontram-se na Tabela 2.

Rochas Metabásicas As características petrográficas exibidas pelas rochas metabásicas permitiram separá-las em quatro conjuntos, ocorrentes preferencialmente em dois domínios distintos:

- a sul do Lineamento Ribeira

a) hornblenda anfibolitos

b) plagioclásio-clorita xistos miloníticos

- a norte do Lineamento Ribeira

c) actinolita anfibolitos

d) diopsídio granofels.

HORNBLENDA ANFIBOLITOS Os hornblenda anfibolitos. representados pelas amostras AP-126B, AP-13 6, AP146, IP-474 e IP-606, constituem-se essencialmente por hornblenda e plagioclásio, este quase totalmente saussuritizado (alterado em epídoto e carbonatos) e atualmente reconhecido pela forma tabular dos agregados de epídoto e restos locais preservados da alteração. Opacos, provavelmente titanomagnetita, envoltos por titanita, ocorrem subordinadamente. Quartzo e apatita são acessórios. Apesar do metamorfísmo, estas rochas ainda preservam parcialmente o arranjo textural original subofítico a ofitico, semelhante ao de diabásios.

Na amostra IP-474, não ocorre saussurita, mas plagioclásio albítico. A granulação mais fina e o arranjo textural decussado a granoblástico, indica uma textura original intergranular, mais típica de basaltos ou, eventualmente, diabásios finos.

A amostra GD-391G, localizada a norte do Lineamento Ribeira, apresenta características petrográficas semelhantes aos hornblenda anfibolitos.

PLAGIOCLÁSIO-CLORITA XISTOS Os quartzo-plagioclásio-clorita xistos miloníticos (com denominação a seguir simplificada para plagioclásio-clorita xistos), representados pelas amostras IP-609 e IP-617A, são rochas compostas predominantemente por clorita, possivelmente derivada da hidratação (retrometamorfismo) de minerais máficos durante a deformação, e subordinadamente quartzo e plagioclásio, em arranjo granolepidoblático gerado por milonitização.

ACTINOLITA ANFIBOLITOS Compõem-se essencialmente de actinolita e epídoto (+ clorita e, localmente, biotita), os últimos em agregados ripiformes, sugerindo pseudomorfose sobre plagioclásios. Actinolita tende a ser fibrosa ou fibro-radiada. Opacos, titanita e algum quartzo ocorrem acessoriamente.

Tabela 1 - Métodos e precisões estimadas para as analises químicas (segundo GEOLAB - Divisão de Laboratórios da Geosol) Table 1 - Methods and estimated precisions for the chemical analyses (according to GEOLAB - Divisão de Laboratórios da Geosol)

\begin{tabular}{|c|c|c|}
\hline $\begin{array}{l}\text { - Elementos } \\
\mathrm{Si}, \mathrm{Ti}, \mathrm{Mg}, \mathrm{Fe}^{\mathrm{t}}, \mathrm{Ca} \in \mathrm{P}\end{array}$ & $\begin{array}{c}\text { Métodos } \\
\text { Fluorescência de raios X com amostras fundidas com tetraborato de lítio e óxido de lantânio }\end{array}$ & $\begin{array}{l}\text { Precisão } \\
\pm 3 \%\end{array}$ \\
\hline $\mathrm{Mn}, \mathrm{Na}$ e K & Dissolução total das amostras com HF-HNO ${ }_{3}$ e determinaçāo por absorçāo atômiça & $\pm 1 \%$ \\
\hline $\mathrm{Sr}$ & Fluorescência de raios $X$ usando técnica do pó prensado & $\pm 5 \%$ \\
\hline $\mathrm{ZreY}$ & Espectrografia óptica de emissão quantitativa & $\pm 5 \%$ \\
\hline
\end{tabular}

$* \mathrm{Fe}^{\mathrm{t}}=$ ferro total, na forma de $\mathrm{Fe}_{2} \mathrm{O}_{3}$ 


\begin{tabular}{|c|c|c|c|c|c|c|c|c|c|c|c|c|c|c|c|c|c|}
\hline $\begin{array}{l}\text { Minerais } \\
\text { Amostras }\end{array}$ & $\mathbf{H b}$ & Act & Saus & PI & $\mathrm{Cl}$ & Aug & Di & $O_{p}$ & $\mathbf{T i}$ & Qz & Mi & Ep & Ap & Carb & Mu & Textura & $\begin{array}{c}\text { Classificaçāo } \\
\text { (petrográfica/genética) }\end{array}$ \\
\hline AP-126B & 40 & $\cdot$ & $45-50$ & - & $5-10$ & - & - & $<5$ & $<5$ & tr & $\cdot$ & - & $\cdot$ & tr & - & decussada & Homblenda anfibolito \\
\hline AP- 136 & 55 & - & $30-35$ & - & - & - & - & $<5$ & $<5$ & 5 & - & - & $<5$ & tr & - & blastofítica & Hornblenda anfibolito (metadiabásio) \\
\hline AP-146 & 40 & - & 30 & - & 15 & - & - & $<5$ & $<5$ & $5-10$ & . & - & tr & $<5$ & - & blastofítica & Hornblenda anfibolito (metadiabásio) \\
\hline IP-474 & $60-65$ & - & $\cdot$ & $20-25$ & 5 & - & - & 5 & - & $<5$ & $\cdot$ & $<5$ & tr & tr & - & decussada & Hornblenda anfibolito \\
\hline IP-606 & $55-60$ & - & $35-40$ & - & $<5$ & - & * & $<5$ & tr & - & - & $=$ & $\mathbf{t r}$ & - & - & blastofítica & Hornblenda anfibolito (metadiabásio) \\
\hline GD-391G & 50 & - & 40 & - & 5 & - & - & 5 & $\mathbf{t r}$ & - & - & - & tr & tr & tr & blasto-intergr & Hornblenda anfibolito (metabasalto) \\
\hline IP-609 & - & - & - & $10-15$ & $35-40$ & - & - & 10 & - & $20-25$ & - & - & $\cdot$ & $15-20$ & - & granolep / mil & Plagioclásio-clorita xisto milonítico \\
\hline IP-617A & $5-10$ & - & - & 25 & 40 & - & - & $<5$ & $<5$ & $15-20$ & $=$ & 5 & te & - & $=$ & granolep / mil & Plagioclásio-clorita xisto milonítico \\
\hline IP-210B & - & 55 & 40 & - & $=$ & - & $=$ & - & tr & - & - & - & $\cdot$ & $\cdot$ & 5 & blastofítica & Actinolita anfibolito (metadiabásio) \\
\hline IP-210C & $\cdot$ & $50-55$ & $35-40$ & - & $\cdot$ & - & - & $<5$ & $<$ & 5 & - & - & - & - & - & blastofítica & Actinolita anfibolito (metadiabásio) \\
\hline IP-210E & - & 50 & 40 & - & - & - & - & $<5$ & $\infty$ & 5 & - & - & - & - & - & blastofítica & Actinolita anfibolito (metadiabásio) \\
\hline IP-210I & $\cdot$ & $55-60$ & 30 & $\cdot$ & - & - & - & 5 & $<5$ & 5 & - & - & $\cdot$ & - & - & decussada & Actinolita anfibolito \\
\hline IP-210J & - & 50 & 45 & $\cdot$ & - & - & - & $<5$ & $\operatorname{tr}$ & $<5$ & $\cdot$ & - & - & - & - & blastofítica & Actinolita anfibolito (metadiabásio) \\
\hline IP-210L & - & 50 & 40 & - & - & - & - & 5 & $\mathbf{t r}$ & $5-10$ & - & - & - & - & - & blastofítica & Actinolita anfibolito (metadiabásio) \\
\hline GD-537 & - & $65-70$ & $30-35$ & $\cdot$ & $\cdot$ & - & - & tr & - & tr & $\cdot$ & - & - & - & tr & blastofítica & Actinolita anfibolito (metadiabásio) \\
\hline GD-541 & - & 50 & $30-35$ & - & 5 & - & - & tr & $5-10$ & 5 & - & - & - & $\cdot$ & - & granonem/decus & Actinolita anfibolito \\
\hline IP-637A & 5 & - & - & 5 & 20 & - & 40 & 5 & - & - & - & - & - & - & - & blasto-intergr & Diopsídio granofels \\
\hline IP-638B & $5-10$ & - & - & $<$ & $25-30$ & - & 35 & $<5$ & - & - & - & - & - & - & - & blasto-intergr & Diopsídio granofels \\
\hline AP-003 & $\delta$ & - & - & 50 & $\alpha$ & $35-40$ & $=$ & 5 & $\operatorname{tr}$ & $<$ & tr & - & tr & - & $=$ & subofit / ofítica & Gabro \\
\hline AP-017 & 5 & - & $=$ & 50 & $\cdot$ & 40 & - & 5 & $=$ & - & tr & - & - & - & - & ofítica & Gabro \\
\hline IP -263 & $\mathbf{t r}$ & - & - & 35 & tr & $60-65$ & - & $\infty$ & - & - & - & - & - & - & - & subofit / intergr & Gabro hidrotermalizado \\
\hline IP-537 & $\delta$ & - & - & $50-55$ & tr & 40 & - & $10-15$ & - & $<5$ & $<5$ & - & $<5$ & - & - & intergr / subofit & Diabásio hidrotermalizado \\
\hline IP-990A & 5 & - & - & 35 & 15 & 25 & - & $10-15$ & - & - & - & - & $<5$ & 5 & - & intergr & Diabásio hidrotermalizado \\
\hline
\end{tabular}


Optou-se por esta nomenclatura devido à inexistência de um nome petrográfico que identificasse corretamente estas rochas, a despeito de não corresponderem à definição clássica de anflbolitos (rochas compostas predominantemente por hornblenda e plagioclásio).

Pelo estudo petrográfico puderam ser distinguidas duas variedades de actinolita anfibolitos, uma predominantemente isótropa (amostras IP-210B, C, E, J, L e GD-537), e outra xistosa (amostras IP-210I e GD-541).

Os detalhes texturais são variados, mas em geral as rochas com estrutura isótropa conservam arranjo ofitico, e devem originalmente corresponder a basaltos ou diabásios finos. Diferenciam-se dos hornblenda anflbolitos pela predominância de actinolita e pela granulação mais fina

Os actinolita anfibolitos com estrutura xistosa distingüemse dos demais por exibirem granulação mais fina e foliação bem desenvolvida - texturas granonematoblástica a decussada - nada conservando do arranjo ígneo original.

DIOPSÍDIO GRANOFELS Diopsídio granofels (amostras IP-637A e IP-638B), situados no Bairro da Ocorrência, são rochas de granulação fina compostas predominantemente de clinopiroxênio (diopsídio) em agregado granoblástico poligonal fino, onde se dispõem ripas milimétricas de prováveis cristais de plagioclásio, atualmente constituídas de albita, clinozoisita e alguma clorita magnesiana. Esta última, usualmente, não só envolve os cristais de diopsídio, mas também forma agregados arredondados, com alguma actinolita, que poderiam representar amígdalas. Megacristais (milimétricos) de diopsídio são raramente observados. Alguma albita e opacos leucoxenizados ocorrem acessoriamente. Estas rochas possivelmente derivam de basaltos.

Rochas Básicas intrusivas GABRO DE APIAÍ As amostras do Gabro de Apiaí (AP-003, AP-017 e IP-263) são compostas por clino e ortopiroxênios (augita e hiperstênio) e plagioclásio (andesina/labradorita), com pequenas quantidades de opacos poiquilíticos. Apresentam leve alteração, deutérica ou hidrotermal, com o aparecimento de hornblenda e, às vezes, biotita nas bordas de augita e hiperstênio. Raro microclínio é observado intersticialmente.

DIQUES DE DIABÁSIO Os diques de diabásios são representados pelas amostras IP-537 e IP-990A.

A amostra IP-537, correspondente ao Dique do Betari, é composta por plagioclásio (andesina), augita (+ pigeonita, em raros grãos, usualmente envolvendo cristais de augita) e opa$\cos$ em arranjo textural intergranular a subofítico. Acessoriamente ocorre apatita. Plagioclásio acha-se medianamente alterado em sericita e/ou clorita. Cristais de augita, embora frescos no centro, tem bordas parcialmente substituídas por hornblenda e/ou biotita vermelha. Quartzo e feldspato alcalino em intercrescimentos gráficos são esparsamente observados.

A amostra IP-990A, que ocorre no Rio Pardo, na Cachoeira do Tamanduá, apresenta granulação média e textura intergranular, sendo composta por cristais ripiformes, submilimétricos a milimétricos, de plagioclásio (andesina), microfissurados e com clorita e carbonato preenchendo as fraturas. Entre os cristais de plagioclásio ocorre carbonato, geralmente envolvido por hornblenda e/ou actinolita e/ou clorita, que representa antigos cristais de piroxênios, agora totalmente substituídos. Opacos estão dispersos por toda a rocha, e apatita é encontrada como mineral acessório.

ASPECTOS GEOQUÍMICOS Os dados analíticos das amostras selecionadas estão dispostos na Tabela 3 , segundo os tipos petrográficos referidos.

Nas figuras que se seguem, as amostras de metabasitos coletados a sul do Lineamento Ribeira são representadas por símbolos preenchidos (cheios), e as coletadas a norte por símbolos vazados. As rochas básicas intrusivas são representadas respectivamente pêlos símbolos + (Gabro de Apiaí) e $\mathrm{x}$ (diabásios).

No geral, as rochas estudadas apresentam muito pouca variação no conteúdo de $\mathrm{SiO}_{2}$, classificando-se como basaltos no diagrama TAS (Figura 3 - Le Maitre 1989), com exceção das amostras IP-617, um andesito, e GD-391G, um basanito. Nesta figura nota-se uma tendência ao enriquecimento em álcalis $\left(\mathrm{Na}_{2} \mathrm{O}+\mathrm{K}_{2} \mathrm{O}\right)$ nos hornblenda anfibolitos, clorita xistos e diabásios.

No diagrama AFM (Figura 4), todos os litotipos exibem caráter tolético, à exceção da amostra IP-210B, que apresenta o maior teor de $\mathrm{Al}_{2} \mathrm{O}_{3}$.

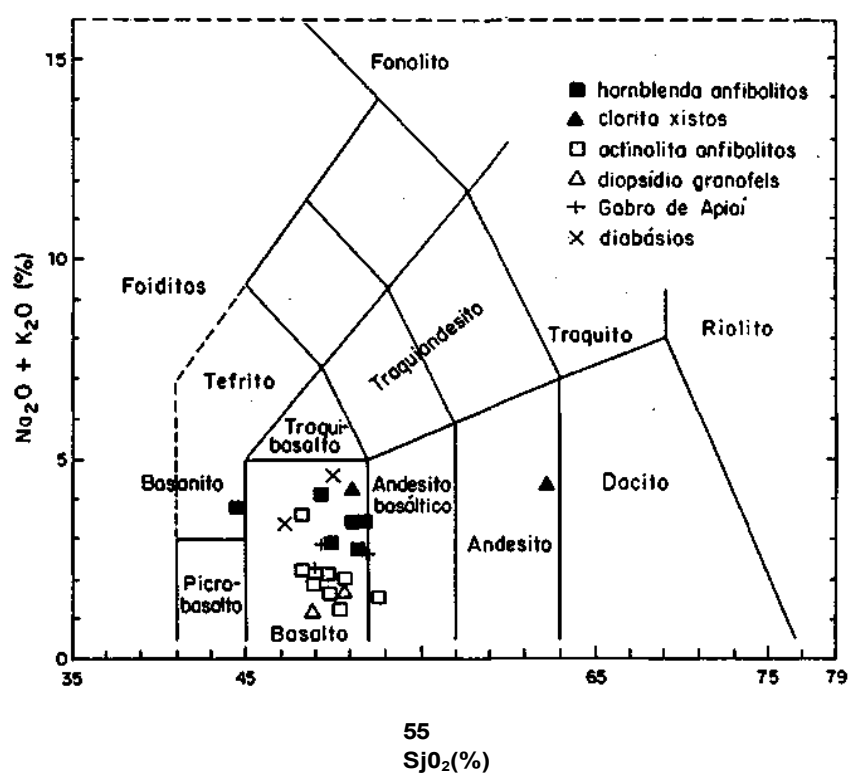

Figura 3 - Classificação petrográfica, segundo o diagrama TAS (Le Maitre 1989).

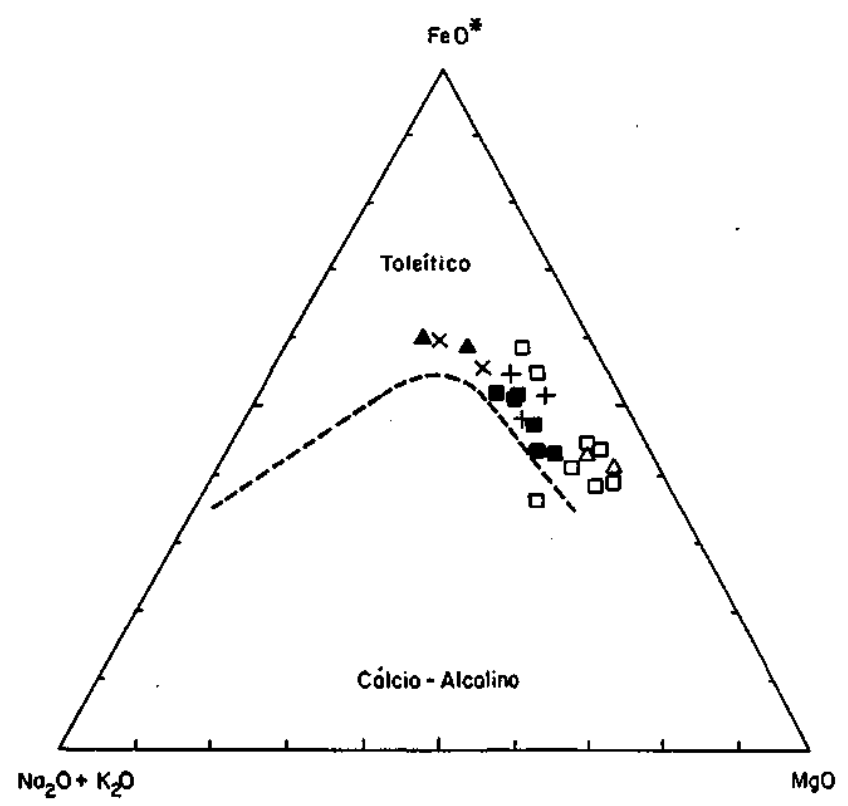

Figure 3 - Petrographical classification, based on the TAS diagram (Le Maitre 1989).

Figura 4 - Diagrama AFM para as rochas básicas e metabásicas (mesma legenda da Figura 3).

Figure 4 - AFM diagram for basic and metabasic rocks (same legend of Figure 3). 
Tabela 3 - Análises químicas para elementos maiores (\%) e para Sr, Zr e Y(ppm) das amostras de rochas básicas e metabásicas. Table 3 - Chemical analyses of major elements (\%) and $\mathrm{Sr}, \mathrm{Zr}$ and $\mathrm{Y}(\mathrm{ppm})$ of the basic and metabasic rocks.

\begin{tabular}{|c|c|c|c|c|c|c|c|c|c|c|c|}
\hline & \multicolumn{2}{|c|}{ Diopsidio Granofels } & \multicolumn{6}{|c|}{$\begin{array}{c}\text { Actinolita Anfibolitos } \\
\text { (nâo foliados) }\end{array}$} & \multicolumn{2}{|c|}{$\begin{array}{c}\text { Actinolita Anfibolitos } \\
\text { (follados) }\end{array}$} & \multirow{2}{*}{$\begin{array}{r}\text { Plagioclá } \\
\mathbf{X}\end{array}$} \\
\hline & IP-637A & IP-638B & GD-537 & IP-210B & IP-210C & IP-210E & IP-210J & IP-210L & IP-210-I & GD.541 & \\
\hline $\mathrm{SiO}_{2}$ & 48,3 & 47,6 & 48,11 & 47,04 & 50,9 & 48,7 & 48,9 & 48,0 & 48,5 & 46,16 & 47,2 \\
\hline $\mathrm{TiO}_{2}$ & 0,47 & 0.45 & 0,42 & 0,40 & 0,42 & 0,35 & 0,38 & 0,41 & 1,10 & 1,27 & 1,60 \\
\hline $\mathrm{Al}_{2} \mathrm{O}_{3}$ & 13,6 & 13,6 & 12,70 & 18,97 & 14,3 & 17,5 & 16,2 & 16,5 & 12,9 & 13,29 & 12,8 \\
\hline $\mathrm{Fe}_{2} \mathrm{O}_{3}$ & 8,5 & 8,1 & 8,82 & 7,59 & 8,9 & 7,2 & 7,8 & 8,0 & 12,7 & 13,64 & 15,5 \\
\hline $\mathrm{MnO}$ & 0,19 & 0,24 & 0,18 & 0,17 & 0,20 & 0,16 & 0,16 & 0,18 & 0,20 & 0,20 & 0,18 \\
\hline $\mathrm{MgO}$ & 8,5 & 9,5 & 10,86 & 8,24 & 8,6 & 7,2 & 7,9 & 8,6 & 7,4 & 6,65 & 5,7 \\
\hline $\mathrm{CaO}$ & 14,6 & 16,8 & 13,76 & 11,74 & 12,0 & 13,3 & 14,6 & 13,2 & 12,8 & 11,74 & 5,3 \\
\hline $\mathrm{Na}_{2} \mathrm{O}$ & 1,3 & $\mathbf{l}, 1$ & 1,31 & 2,14 & 1,3 & 1,8 & 1,1 & 1,6 & 2,0 & 2,02 & 3,9 \\
\hline $\mathrm{K}_{2} \mathrm{O}$ & 0,04 & 0,04 & 0,32 & 1,41 & 0,24 & 0,14 & 0,15 & 0,25 & 0,06 & 0,13 & 0,03 \\
\hline $\mathrm{P}_{2} \mathrm{O}_{5}$ & 0,07 & 0,09 & 0,22 & 0,18 & 0,07 & 0,05 & 0,05 & 0,06 & 0,12 & 0,26 & 0,15 \\
\hline TOTAL & 95,57 & 97,52 & 96,70 & 97,88 & 96,93 & 96,40 & 97,24 & 96,80 & 97,78 & 95,36 & 92,36 \\
\hline $\mathrm{Sr}$ & 120 & 140 & 78 & 180 & 110 & 180 & 170 & 140 & 170 & 160 & 52 \\
\hline $\mathrm{Zr}$ & 37 & 69 & 12 & 28 & 52 & 16 & 30 & 30 & 74 & 80 & 106 \\
\hline \multirow[t]{3}{*}{$\mathbf{Y}$} & 11 & 25 & 17 & 25 & 20 & 11 & 14 & 11 & 32 & 20 & 52 \\
\hline & \multicolumn{6}{|c|}{ Hornblenda Anffbolitos } & \multicolumn{3}{|c|}{ Gabro de Apiaj } & \multicolumn{2}{|c|}{ Diabásios } \\
\hline & AP-126B & AP-136 & AP-146 & IP-606 & IP-474 & GD-391G & IP-263 & AP-003 & AP-017 & IP-537 & IP-990A \\
\hline $\mathrm{SiO}_{2}$ & 50,1 & 50,2 & 49,6 & 48,8 & 48,4 & 43,19 & 49,09 & 48,06 & 51,4 & 49,43 & 45,0 \\
\hline $\mathrm{TiO}_{2}$ & 1,50 & 1,70 & 1,5 & 1,60 & 2,50 & 1,12 & 1,10 & 1,24 & 0,78 & 3,37 & 2,30 \\
\hline $\mathrm{Al}_{2} \mathrm{O}_{3}$ & 13,3 & 13,8 & 13,9 & 13,4 & 12,8 & 14,71 & 12,66 & 14,19 & 14,7 & 12,98 & 15,2 \\
\hline $\mathrm{Fe}_{2} \mathrm{O}_{3}$ & 12,5 & 9,9 & 10,1 & 10,2 & 13,9 & 13,59 & 12,48 & 12,78 & 9,3 & 14,70 & 12,0 \\
\hline $\mathrm{MnO}$ & 0,28 & 0,19 & 0,18 & 0.19 & 0,24 & 0,27 & 0,22 & 0,21 & 0,20 & 0,21 & 0,21 \\
\hline $\mathrm{MgO}$ & 7,3 & 7,1 & 8,4 & 9,2 & 7,5 & 8,02 & 8,28 & 6,69 & 6,4 & 4,43 & 5,4 \\
\hline $\mathrm{CaO}$ & 8,2 & 11,7 & 9,4 & 11,6 & 8,6 & 11,99 & 13,91 & 12,14 & 13,3 & 8,46 & 11,5 \\
\hline $\mathrm{Na}_{2} \mathrm{O}$ & 3,2 & 2,6 & 3,1 & 2,7 & 3,8 & 2,14 & 1,97 & 2,52 & 2,4 & 2,94 & 2,3 \\
\hline $\mathrm{K}_{2} \mathrm{O}$ & 0,08 & 0,08 & 0,18 & 0,14 & 0,27 & 1,56 & 0,29 & 0,31 & 0,21 & 1,59 & 0,98 \\
\hline $\mathrm{P}_{2} \mathrm{O}_{5}$ & 0,15 & 0.18 & 0,15 & 0,16 & 0,20 & 0,19 & 0,24 & 0,27 & 0,10 & 0,63 & 0,39 \\
\hline TOTAL & 96,61 & 97,45 & 96,51 & 97,99 & 98,21 & 96,78 & 100,24 & 98,41 & 98,79 & 98,74 & 95,28 \\
\hline Sr & 300 & 330 & 440 & 480 & 260 & 370 & - & 150 & 140 & - & 1250 \\
\hline $\mathbf{Z r}$ & 104 & 94 & 92 & 112 & 140 & 80 & - & 80 & 16 & - & 190 \\
\hline $\mathbf{Y}$ & 38 & 29 & 22 & 36 & 45 & 13 & $\therefore$ & 30 & 14 & - & 64 \\
\hline
\end{tabular}

A Tabela 3 e a Figura 5 ( $\mathrm{MgO} \times$ maiores), claramente discriminam os metabasitos em dois grupos, especialmente quanto aos teores em $\mathrm{Ca}, \mathrm{Ti}, \mathrm{Fe}^{\mathrm{t}}$ e $\mathrm{Na}$.

O primeiro grupo compreende os hornblenda anfibolitos, e caracteriza-se por teores relativamente mais altos em $\mathrm{Na}, \mathrm{Fe}$ e Ti e mais baixos de $\mathrm{Al}$ e $\mathrm{Ca}$. Os actinolita anfibolitos foliados e os plagioclásio-clorita xistos mostram afinidades químicas com este grupo. Os plagioclásio-clorita xistos, exibem no entanto baixo $\mathrm{CaO}$ e altos $\mathrm{Fe}_{2} \mathrm{O}_{3}{ }^{\mathrm{t}}$ e $\mathrm{Na}_{2} \mathrm{O}$.

No segundo grupo acham-se os actinolita anfibolitos isótropos, em geral com altos teores em $\mathrm{Ca}$ e $\mathrm{Al}$ e baixos em $\mathrm{Na}$, $\mathrm{Fe}^{\mathrm{t}} \mathrm{e} \mathrm{Ti}$, contrariamente aos hornblenda anfibolitos. Os diopsídio granofels são quimicamente correlates a eles.

Há, também, um claro incremento nos teores de $\mathrm{Zr}, \mathrm{TiO}_{2}$ e $\mathrm{P}_{2} \mathrm{O}_{5}$ nos hornblenda anfibolitos em relação aos actinolita anfibolitos.

As rochas destes dois grupos correspondem, de uma maneira geral, àquelas que se encontram a sul (hornblenda anfibolitos) e a norte (os actinolita anfibolitos) do Lineamento Ribeira (Figura 2).

Os dados analíticos obtidos para estes dois grupos, quando comparados com aqueles fornecidos pela literatura especializada (e.g. Wilson 1989), mostram grande semelhança dos hornblenda anfibolitos com os basaltos de cadeias mesooceânicas e dos actinolita anfibolitos com os basaltos de arcos

de ilhas, considerando-se $\mathrm{TiO}_{2}, \mathrm{Fe}_{2} \mathrm{O}_{3}{ }^{\mathrm{t}}, \mathrm{P}_{2} \mathrm{O}_{5}, \mathrm{Sr}, \mathrm{Zr}$ e $\mathrm{Y}$ os elementos discriminantes.

Os óxidos e elementos traços das amostras do Gabro de Apiaí, como visto na Figura 5, mostram características muito similares às dos basaltos de cadeias meso-oceânicas. Embora tratem-se de gabros e não de basaltos. podendo então ser questionado o uso de diagramas discriminantes definidos originalmente para suites vulcânicas, Wilson (1989) lembra que rochas gabróides dragadas de fundos oceânicos mostram uma considerável sobreposição em termos de composição com os basaltos de cadeias meso-oceânicas.

Os diabásios discriminam-se do conjunto pelos altos teores de Ti, P, Fe $\mathrm{t}^{\mathrm{t}}, \mathrm{Sr}, \mathrm{Zr}$ e Y, e sua composição química é correlacionável àquelas apresentadas por Piccirillo et al. (1990) para amostras de diques de diabásio do Lineamento de Guapiara, mais especificamente para aquelas do grupo de alto $\mathrm{TiO}_{2}(>2 \%$; HTi) e elementos incompatíveis.

Comparando-se os teores de elementos traços das rochas analisadas com os fornecidos por Condie (1989), constatou-se que os actinolita anfibolitos se caracterizam como basaltos de arcos de ilha $(\mathrm{Zr} / \mathrm{Y}<3)$, predominantemente do tipo cálcio-alcalino $(\mathrm{Ti} / \mathrm{Y}<85)$.

O diagrama discriminante Zr x Zr/Y (Pearce \& Norry 1979 -Figura 6), por sua vez, mostra os hornblenda anfibolitos dentro do campo dos basaltos de cadeias meso-oceânicas e os actinolita anfibolitos no campo de basaltos de arcos de ilhas. 

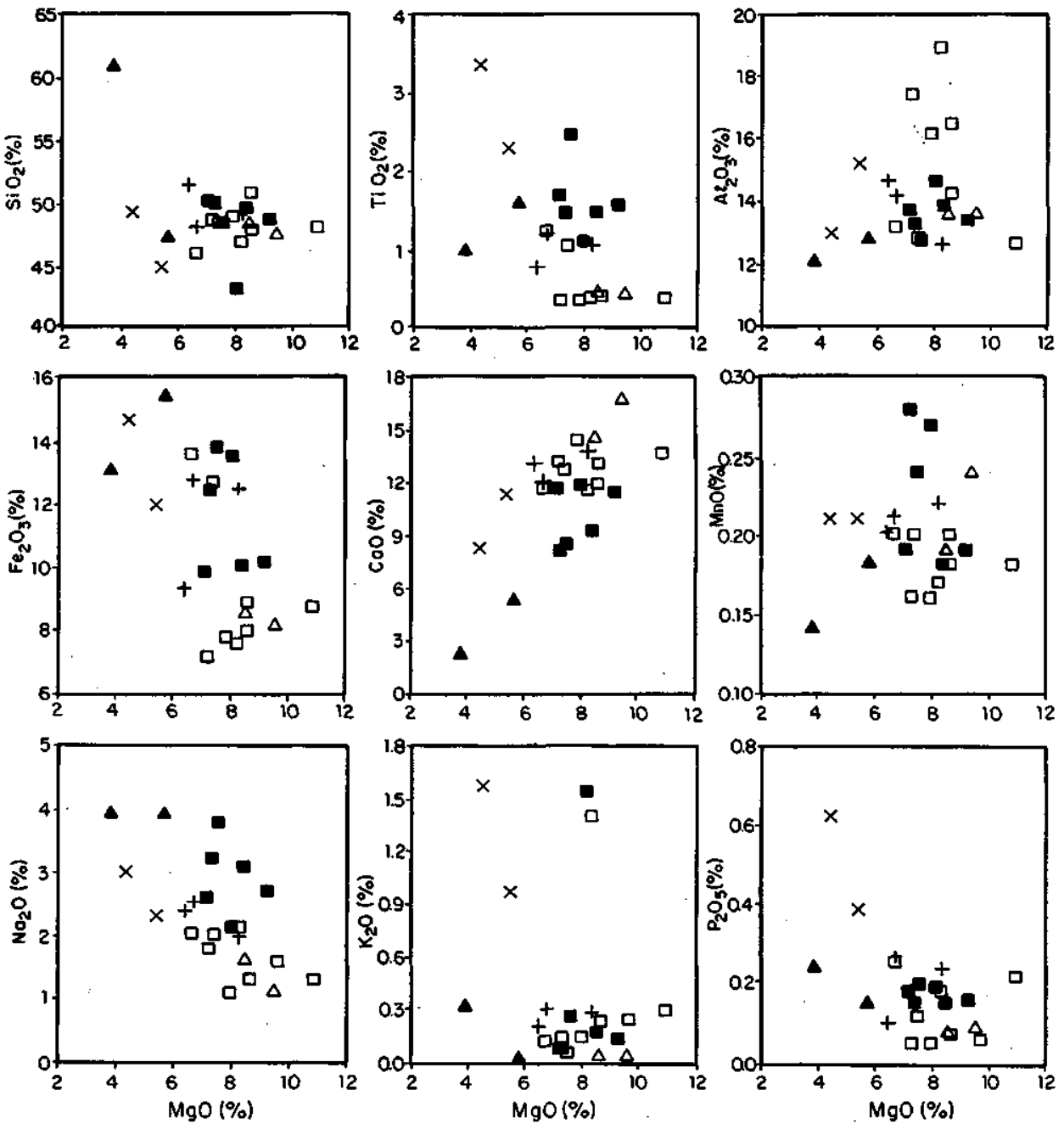

Figura 5 - Diagrama de variação MgO x demais óxidos para as rochas básicas e metabásicas (mesma legenda da Figura 3).

Figure 5 - Variation diagram $\mathrm{MgO}$ x other oxides for the basic and metabasic rocks (same legend of Figure 3).

$\mathrm{Na}$ Figura 7 (diagrama $\mathrm{Zr} \times \mathrm{TiO}_{2}$ de Pharaoh \& Pearce 1984, apud Condie 1989), os actinolita anfibolitos se incluem no campo dos basaltos de arco de ilhas e os hornblenda anfibolitos no dos basaltos de cadeias meso-oceânicas. A título de ilustração, lançou-se a amostra IP-990A (diabásio), e seus valores coincidiram com o campo dos basaltos intraplacas.

CONCLUSÕES A análise dos dados petrográficos e químicos obtidos permite tecer algumas considerações. As rochas apresentam grande homogeneidade quanto ao conteúdo em $\mathrm{SiO}_{2}$, com apenas duas delas classificando-se fora do campo dos basaltos. No que concerne aos elementos maiores, todos as rochas têm natureza toleítica quanto aos elementos maiores.

O Gabro de Apiaí exibe características geoquímicas comparáveis com os basaltos de cadeias meso-oceânicas.

Os diques de diabásios são fortemente enriquecidos em Ti, $\mathrm{P}, \mathrm{Fe}^{\mathrm{t}}, \mathrm{Sr}, \mathrm{Zr}$ e Y; e sua composição química coincide, na sua maior parte, com as do magmatismo meso-cenozóico da Bacia do Paraná, especialmente com as dos diques de diabásio da porção norte do Arco de Ponta Grossa (Lineamento de Guapiara). Também guardam semelhanças com basaltos de platôs e rifts continentais.

Os metabasitos analisados pertencem a dois grupos químicos: os enriquecidos em $\mathrm{Na}, \mathrm{Fe}$, $\mathrm{Ti}, \mathrm{Zr}$, $\mathrm{Y}$ e $\mathrm{Sr}$ e os enriquecidos em Ca e Al.
Os metabasitos do primeiro grupo correspondem aos hornblenda anfibolitos, e com os quais os plagioclásio-clorita xistos e os actinolita anfibolitos foliados apresentam similaridades químicas.

Aqueles enriquecidos em $\mathrm{Ca}$ e $\mathrm{Al}$ e pobres em $\mathrm{P}, \mathrm{Ti}, \mathrm{Zr}, \mathrm{Y}$ e Sr, correspondem aos actinolita anfibolitos isótropos e diopsídio granofels.

Estes grupos mostram similaridade química, quando comparados com os dados da literatura especializada, com os basaltos de cadeias meso-oceânicas (hornblenda anfibolitos, plagioclásio-clorita xistos e actinolita anfibolitos foliados) e com os basaltos de arcos de ilhas (actinolita anfibolitos isótropos e diopsídio granofels).

Os metabasitos do Subgrupo Ribeira diferenciam-se assim, grosso modo, em dois grupos: um a norte do Lineamento Ribeira, com características semelhantes aos basaltos de arcos de ilhas modernos; e outro a sul do Lineamento Ribeira guardando semelhanças com basaltos de cadeias meso-oceânicas modernas.

Embora a interpretação paleotectônica baseada unicamente em dados químicos de rochas, e sua comparação com ambientes tectônicos modernos, possa ser considerada precária, não há incoerência entre as associações deposicionais observadas na área estudada com os ambientes de fundo oceânico e de arcos de ilha (Campanha 1991).

Como os teores de $\mathrm{SiO}_{2}$ dos metabasitos são particularmente homogêneos, supõe-se que as diferenças químicas en- 


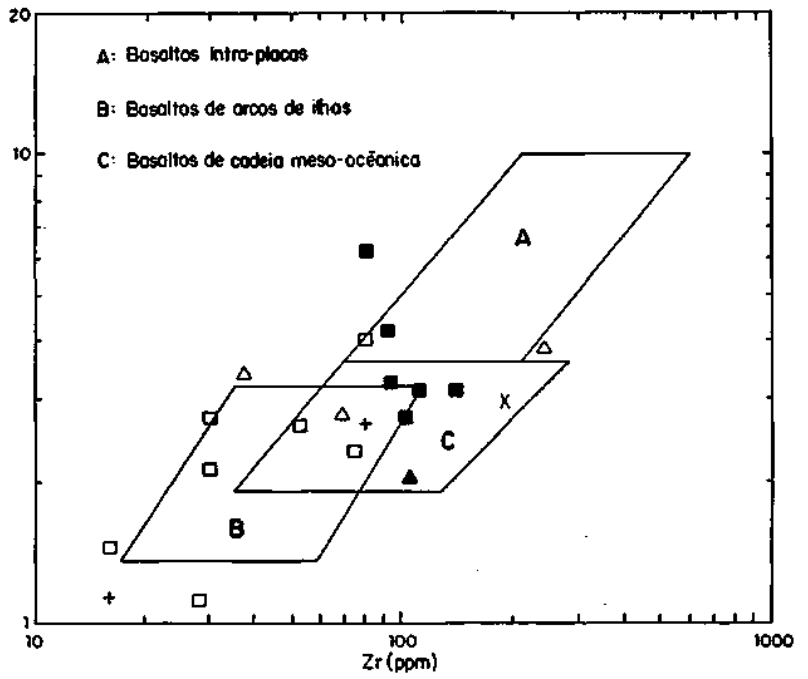

Figura 6 - Diagrama discriminante $\mathrm{Zr} / \mathrm{Y} \times \mathrm{Zr}$ (Pearce \& Norry 1979) para as rochas básicas e metabásicas (mesma legenda da Figura 3).

Figure 6 - Discriminating diagram Zr/Y x Zr (Pearce \& Norry 1979) for the basic and metabasic rocks (same legend of Figure 3 ).

tre aqueles a norte e a sul do Lineamento Ribeira reflitam características paleotectônicas, que poderiam ser explicadas por várias hipóteses: a) justaposição tectônica de dois terrenos distintos; b) diferenciação de arco de ilhas, mais imaturo a sul que a norte; c) ambiente de retro-arco, apresentando rochas transicionais entre arco de ilhas e basaltos de expansão de fundo oceânico em bacias de retro-arco; d) derivação deste material por um processo envolvendo fusão parcial de uma fonte heterogênea do manto (como por exemplo em Corrêa \& Girardi 1989).

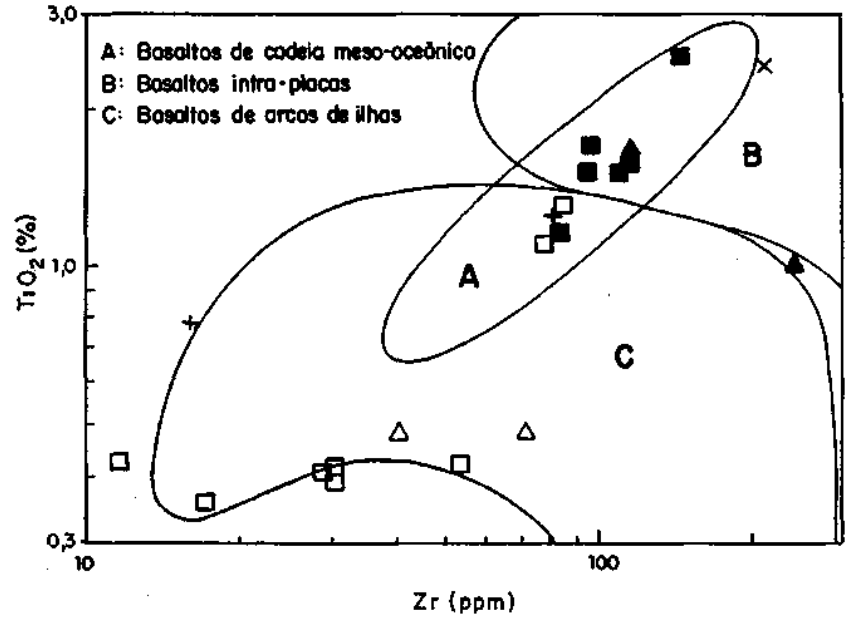

Figura 7 - Diagrama discriminante Zr x 7702 (Pharaoh \& Pearce 1984, apud Condie 1989), para as rochas básicas e metabásicas (mesma legenda da Figura 3).

Figure 7 - Discriminating diagram Zr x TiCh (Pharaoh \& Pearce 1984, apud Condie 1989), for the basic and metabasic rocks (same legend of Figure 3).

Frasca et, al. (1990), em estudo de rochas metabásicas da Formação Agua Clara, na região de Araçaíba, a noroeste da área aqui abordada, também apontaram dois possíveis eventos magmáticos de natureza toleítica, um correspondendo a basaltos de fundo oceânico transicional ou de arco insular imaturo, e outro associado a basaltos shoshoníticos, indicativos de margem continental ativa com maior grau de maturidade.

Estudos mais aprofundados, envolvendo geoquímica isotópica e elementos de Terras Raras, trarão avanços no esclarecimentos destes pontos.

\section{REFERÊNCIAS}

ALMEIDA, F.F.M. de; AMARAL, G.; CORDANI, U.G.; KAWASHITA, K. 1973. The precambrian evolution of the south american cratonic margin south of Amazon River. In: NAIRN, E.M. \& STEHLI, F.G. 1973. The ocean basins and margins. New York, Plenun. v. 1, p. 411-446.

CAMPANHA, G.A.C. 1991. Tectônica proterozóica no alto e Médio Vale do Ribeira, Estados de São Paulo e Paraná. São Paulo. 296p. (Tese de Doutoramento, Instituto de Geociências da Universidade de São Paulo).

CAMPANHA, G.A. da C.; BISTRICHI, C.A.; ALMEIDA, M.A. de 1987. Considerações sobre a organização litoestratigráfiça e evolução tectônica da faixa de dobramentos Apiaí. In: SIMPÓSIO SUL-BRASILEIRO de GEOLOGIA, 3. Curitiba, 1987. Atas... Curitiba, SBG. v. 2, p. $725-742$.

CAMPANHA, G.A da C., GIMENEZ FILHO, A., SADOWSKI, G.R. 1994 Tectônica da Faixa Ribeira. In: Congr. Bras. Geol., 38. Balneário de Camboriú, 1994. Bol. Res. Expandidos... Balneário de Camboriú, SBG. v.l.p.271-272.

CAMPANHA, G. A. da C., GIMENEZ FILHO, A., BISTRICHI, C.A. 1995. Geologia da Folha Itararé em 1:250 000. In: Simp. Geol. Sudeste, 4. Águas de São Pedro, 1995. Boletim... Águas de São Pedro, SBG. p.111

CAMPOS NETO, M da C., FIGUEIREDO, M. C. H. 1995. The Rio Doce Orogeny, Southeastern Brazil. Journal of South American Earth Science, 8(2): 143-162.

CHIODI FILHO, C. 1984. Contribuição à geologia das regiões sul paulista $\mathrm{e}$ leste paranaense, Grupos Açungui e Setuva. In: CONGRESSO BRASILEIRO de GEOLOGIA, 33. Rio de Janeiro, 1984. Anais... Rio de Janeiro, SBG. v.5, p. 2394-2406

CONDIE, K.C. 1989. Geochemical changes in basalts and andesites across the Archean-Proterozoic boundary: Identification and significance. Lithos, 23:1-18.

CORREA, C.T., GIRARDI, V.A.V. 1989. Estudo geoquímico e petrológico dos anfibolitos da região de Cássia, MG. Rev. Bras. Geoc., 19(1): $37-50$.
DAITX, E.C., TEIXEIRA, W., ZANARDO, A. 1990. Geologia e geocronologia do metagabro de Apiá, Vale do Ribeira, SP. In: CONGR BRÁS. GEOL., 36. Natal, 1990. Boletim de Resumos... Natal, SBG. p. 341.

FRASCA, M.H.B.O., FIGUEIREDO, M.C.H., ALMEÍDA, M.A., COUTINHO, J.M.V.C. 1990. Petrografia e geoquímica da Formação Agua Clara - Região de Araçaíba, SP. Boletim do Instituto de GeociênciasUSP, Série Cientifica, v.21, p. 73-92.

HASUI, Y., CARNEIRO, C.D.R., COIMBRA, A.M. 1975. The Ribeira Folded Belt. Rev.Bras.Geoc., 5 (4):257-262.

LE MAITRE, R.W. (ed.). 1989. A classification ofigneous rocks andglossary of terms: Recommendations of the International Union of Geológical Sciences - Subcommission on the Systematics of Igneous Rocks. Oxford. Blackwell Scientific Publications. 193p.

PEARCE, J. A. \& NORRY, M.J. 1979 Petrogenetic implications of Ti, Zr, Y and $\mathrm{Nb}$ variations in volcanic rocks. Conírib. Mineral. Petrol., 69:3347.

PICCIRILLO, E.M., BELLIENI, G., CAVAZZINI, G., COMIN-CHIARAMONTI, P., PETRINI, R., MELFI, A.J., PINESE, J.P.P., ZANTADESCHI, P., DE MIN, A. 1990. Lower Cretaceous tholeiitic dyke swarms from the Ponta Grossa Arch (southeast Brazil): Petrology, Sr-Nd isotopes, and genetic relationships with the Paraná flood volcanics. Chemical Geology, 89:19-48.

WILSON, M. 1989. Igneous petrogenesis: a global tectonic approach. London, Unwin Hyman. 466 p. Revisão aceita em 15 de junho de 1997 